\title{
Correction to: Classification of Healthy Subjects and Alzheimer's Disease Patients with Dementia from Cortical Sources of Resting State EEG Rhythms: Comparing Different Approaches
}

C. Del Percio, V. Bevilacqua, A. Brunetti, R. Lizio, A. Soricelli,

R. Ferri, F. Nobili, L. Gesualdo, G. Logroscino, M. De Tommaso, A. I. Triggiani, M. Blūma, G. B. Frisoni, and C. Babiloni

\section{Correction to:}

Chapter "Classification of Healthy Subjects and Alzheimer's Disease Patients with Dementia from Cortical Sources of Resting State EEG Rhythms: Comparing Different Approaches" in: L. Masia et al. (Eds.): Converging Clinical and Engineering Research on Neurorehabilitation III, BIOSYSROB 21, https://doi.org/10.1007/978-3-030-01845-0_196

The original version of the chapter was inadvertently published without the author and the affiliation, "M Blūma and University of Rome "La Sapienza", Rome, Italy" in the opening page of the chapter, which have now been included. The correction chapter has been updated with the change. 